\title{
Impact of the Epithelial Lining Fluid Milieu on Amikacin Pharmacodynamics Against Pseudomonas aeruginosa
}

\author{
Aaron J. Heffernan ${ }^{1,2}$ (D) Fekade B. Sime ${ }^{2,3} \cdot$ Sazlyna Mohd Sazlly Lim² ${ }^{2,4} \cdot$ Saiyuri Naicker $^{2,3} \cdot$ Katherine T. Andrews $^{5}$. \\ David Ellwood ${ }^{1,6} \cdot$ Jeffrey Lipman ${ }^{7,8} \cdot$ Keith Grimwood $^{1,6} \cdot$ Jason A. Roberts ${ }^{2,3,7,8}$
}

Accepted: 18 March 2021 / Published online: 2 April 2021

(c) The Author(s) 2021

\begin{abstract}
Background Even though nebulised administration of amikacin can achieve high epithelial lining fluid concentrations, this has not translated into improved patient outcomes in clinical trials. One possible reason is that the cellular and chemical composition of the epithelial lining fluid may inhibit amikacin-mediated bacterial killing.

Objective The objective of this study was to identify whether the epithelial lining fluid components inhibit amikacin-mediated bacterial killing.

Methods Two amikacin-susceptible (minimum inhibitory concentrations of 2 and $8 \mathrm{mg} / \mathrm{L}$ ) Pseudomonas aeruginosa isolates were exposed in vitro to amikacin concentrations up to $976 \mathrm{mg} / \mathrm{L}$ in the presence of an acidic $\mathrm{pH}$, mucin and/or surfactant as a means of simulating the epithelial lining fluid, the site of bacterial infection in pneumonia. Pharmacodynamic modelling was used to describe associations between amikacin concentrations, bacterial killing and emergence of resistance.

Results In the presence of broth alone, there was rapid and extensive $\left(>6-\log _{10}\right)$ bacterial killing, with emergence of resistance identified in amikacin concentrations $<976 \mathrm{mg} / \mathrm{L}$. In contrast, the rate and extent of bacterial killing was reduced $\left(\leq 5-\log _{10}\right)$ when exposed to an acidic $\mathrm{pH}$ and mucin. Surfactant did not appreciably impact the bacterial killing or resistance emergence when compared with broth alone for either isolate. The combination of mucin and an acidic $\mathrm{pH}$ further reduced the rate of bacterial killing, with the maximal bacterial killing occurring $24 \mathrm{~h}$ following initial exposure compared with approximately $4-8 \mathrm{~h}$ for either mucin or an acidic $\mathrm{pH}$ alone.

Conclusions Our findings indicate that simulating the epithelial lining fluid antagonises amikacin-mediated killing of $P$. aeruginosa, even at the high concentrations achieved following nebulised administration.
\end{abstract}

Aaron J. Heffernan

aaron.heffernan@griffithuni.edu.au

1 School of Medicine, Griffith University, Gold Coast, QLD, Australia

2 Centre for Translational Anti-infective Pharmacodynamics, School of Pharmacy, The University of Queensland, Cornwall St, Woolloongabba, QLD 4102, Australia

3 Faculty of Medicine, University of Queensland Centre for Clinical Research, The University of Queensland, Brisbane, QLD, Australia
4 Department of Medicine, Faculty of Medicine and Health Sciences, Universiti Putra Malaysia, Serdang, Malaysia

5 Griffith Institute for Drug Discovery, Griffith University, Nathan, QLD, Australia

6 Gold Coast Health, Southport, QLD, Australia

7 Department of Intensive Care Medicine, Royal Brisbane and Women's Hospital, Brisbane, QLD, Australia

8 Division of Anaesthesiology Critical Care Emergency and Pain Medicine, Nîmes University Hospital, University of Montpellier, Nîmes, France 


\section{Key Points}

The epithelial lining fluid inhibits amikacin-mediated bacterial killing and amplifies the emergence of resistance, despite the high concentrations attained in the epithelial lining fluid following nebulisation

Future dosing formulation and design should account for the negative impact of the epithelial lining fluid to enhance bacterial killing and mitigate against the emergence of resistance

\section{Introduction}

Ventilator-associated pneumonia (VAP) affects up to $38 \%$ of mechanically ventilated patients, with an attributable mortality of $13 \%[1,2]$. Patient outcomes are enhanced by receiving antibiotics promptly that are active against the causative pathogen $[1,2]$. Outcomes could be further improved by optimising the free antibiotic concentrations in epithelial lining fluid (ELF), the principal site of infection in VAP [3, 4].

Current guidelines recommend that patients with VAP receive intravenous antibiotics [5]. However, attaining target antibiotic exposures in the ELF is limited by the blood-alveolar barrier, which inhibits antibiotics diffusing into the site of infection [6]. The ELF penetration of anti-pseudomonal aminoglycosides, such as amikacin, is only about $8 \%$ of the concurrent plasma concentration [7]. As patient mortality is minimised when the aminoglycoside maximum concentration $\left(C_{\max }\right)$ relative to the pathogen minimum inhibitory concentration (MIC) exceeds eightfold, the impaired diffusion into the ELF following intravenous administration may be a key determinant of reduced clinical response rates for patients with VAP when receiving intravenous aminoglycosides [5, 8, 9]. Given the reduced amikacin ELF penetration, there has been renewed interest in nebulised therapy for the treatment of Pseudomonas aeruginosa, a causative pathogen in $16 \%$ of patients with VAP, and where amikacin retains activity for $>90 \%$ of multi-drug-resistant isolates $[10,11]$.

Inhaled delivery methods bypass the blood-alveolar barrier, leading to aminoglycoside concentrations within the ELF that are at least 35-fold greater than those achieved with intravenous administration. Such high antibiotic concentrations correspond to a $C_{\max } / \mathrm{MIC}>8$ for susceptible pathogens [7, 12-14]. Despite high amikacin concentrations in ELF following inhalation, no mortality benefit was demonstrated for adjunct inhaled amikacin in two recently published, randomised controlled clinical trials [15-17]. In addition to methodological issues, such as poorly optimised ventilator settings, nebuliser selection and choice of patient cohorts, possible pharmacokinetic/pharmacodynamic reasons why a clinical benefit was not demonstrated may include heterogeneity in antibiotic lung deposition [18-20], and an inhibitory effect of the ELF, which contains a complex mixture of mucins [21, 22] and surfactant [23] and has an acidic $\mathrm{pH}[24]$.

Mucins are glycoproteins that comprise the main macromolecular components of the mucous gel forming the ELF [25]. They have a major protective barrier and clearance function against pathogens. Mucins can also bind amikacin reducing the unbound, pharmacologically active amikacin concentration by up to $60 \%$ [21]. Similarly, surfactant, a charged phospholipoprotein produced by type II alveolar cells, has been shown to reduce the unbound fraction of aminoglycosides as much as $17 \%$ [23]. The decreased antibiotic free fraction is one potential mechanism mediating impaired aminoglycoside activity in vivo. Indeed, a recent study reported the MIC of $P$. aeruginosa increased 64-fold following the addition of a physiologically relevant concentration of mucin [22]. Moreover, acidification within the bronchi of patients with pneumonia $(\mathrm{pH} 6.48 \pm 0.12$; mean \pm standard deviation) reduces intracellular aminoglycoside uptake and bacterial killing [24, 26]. From these data, it is apparent that surfactant, an acidic $\mathrm{pH}$ and the presence of mucin likely contribute to altered aminoglycoside pharmacodynamics; however, it is unclear how these factors together, simulating the ELF milieu, may influence bacterial killing. Hence, this in vitro study aimed to describe the impact of mucins, surfactant and an acidic $\mathrm{pH}$, alone and in combination, on amikacin-mediated $P$. aeruginosa bacterial killing and the emergence of amikacin resistance.

\section{Materials and Methods}

\subsection{Antimicrobial Agents}

Analytical reference standards of amikacin (LRAA5755; Sigma-Aldrich, Darmstadt, Germany) were used for in vitro susceptibility testing, preparing amikacin-containing cationadjusted Mueller-Hinton (Ca-MH) agar for quantification of a less-susceptible bacterial population and static time-kill studies. Stock solutions were diluted in sterile water and stored at $-80{ }^{\circ} \mathrm{C}$.

\subsection{Bacterial Isolates}

The clinical $P$. aeruginosa isolates used in this study (\#CTAP23 and \#CTAP40) were sourced from tertiary hospitals in Brisbane, QLD, Australia, from critically ill patients. A $P$. aeruginosa (ATCC 27853) control isolate was used for MIC testing. Isolates were stored in $\mathrm{Ca}-\mathrm{MH}$ broth with $20 \%$ glycerol v/v at $-80{ }^{\circ} \mathrm{C}$. Prior to susceptibility testing 
and static time-kill study experiments, isolates were grown overnight on Ca-MH agar at $37{ }^{\circ} \mathrm{C}$. A McFarland 0.5 standard was prepared using colonies of a similar morphology and further diluted in Ca-MH broth for in vitro susceptibility testing at the desired inoculum. For static time-kill studies, the resultant bacterial suspension was grown at $37{ }^{\circ} \mathrm{C}$ with constant agitation until a bacterial inoculum of $\sim 1 \times 10^{8}$ colony-forming units $(\mathrm{CFU}) / \mathrm{mL}$ was obtained based on a prior growth curve analysis.

\subsection{In Vitro Susceptibility Testing}

Minimum inhibitory concentration testing was performed in accordance with the Clinical and Laboratory Standards Institute (CLSI) and European Committee on Antimicrobial Susceptibility Testing broth microdilution guidelines $[27,28]$. Briefly, serial two-fold dilutions of amikacin were prepared in Ca-MH broth in round-bottom and flat-bottom 96-well plates for CLSI and European Committee on Antimicrobial Susceptibility Testing methods, respectively. Bacterial colonies were added to sterile water to an equivalent turbidity of McFarland 0.5 standard. Sufficient volume of this bacterial suspension was added to $\mathrm{Ca}-\mathrm{MH}$ broth to attain a final well bacterial concentration of $\sim 5.5 \times 10^{6} \mathrm{CFU} / \mathrm{mL}$. The inoculated plates were incubated for $16-20 \mathrm{~h}$ at $37{ }^{\circ} \mathrm{C}$. In accordance with the CLSI guidelines, the round-bottom 96-well plates were visually inspected; the lowest amikacin concentration with no visible growth was defined as the MIC. A Multiskan FC Microplate Photometer (Thermo Fisher Scientific, Ratastie, Finland) was used to determine the optical density of each well in the flat-bottom 96-well plate. The MIC was taken as the concentration of antibiotic resulting in an optical density $<0.1$ that of the growth control. Minimum inhibitory concentration tests using both CLSI and European Committee on Antimicrobial Susceptibility Testing methods were performed on two separate occasions with four replicates for each isolate and method. The MIC was the modal value for each method.

\subsection{Static Time-Kill Assay}

Static time-kill experiments were performed to assess the bacterial killing and emergence of amikacin resistance in the simulated ELF. A bacterial suspension was grown in Ca-MH broth to achieve the desired inoculum of $\sim 1 \times 10^{8} \mathrm{CFU} / \mathrm{mL}$, a bacterial density identified in over $26 \%$ of patients with VAP [29]. The bacterial suspension was centrifuged for 10 min at $4400 \mathrm{~g}$. The resulting pellet was re-suspended in the desired growth media for each combination of ELF variables (Ca-MH broth alone, mucin, surfactant and $\mathrm{pH}$ adjustment) as outlined below. After $24 \mathrm{~h}$, the bacterial suspension was centrifuged and re-suspended in fresh antibiotic media and the associated environmental condition(s).
To simulate and maintain the acidic $\mathrm{pH}$ of the ELF during an acute infection, a sodium phosphate buffer was prepared. In brief, a sterile solution of sodium phosphate monobasic (ChemSupply, Gillman, Australia, batch number 268025) and sodium phosphate dibasic (Sigma-Aldrich, Darmstadt, Germany, batch number K46477180512) reagent was diluted in Ca-MH broth to achieve a final concentration of $0.1 \mathrm{M}$ for both compounds. The $\mathrm{pH}$ was subsequently adjusted to 6.48 and 7.40 for the ELF milieu simulation and control, respectively, using sterile hydrochloric acid [24]. This was shown previously to maintain the desired $\mathrm{pH}$ within 0.20 of the target after $24 \mathrm{~h}$. Previous growth controls for both isolates did not show a difference in bacterial growth between isolates exposed to the buffer or in Ca-MH broth alone. Porcine mucin (Sigma Aldrich, batch number SLBV4979) was added to the appropriate experimental arm to a final concentration of 5\% w/v to simulate sputum [30]. A surfactant preparation used in clinical practice (Poractant alfa; Emerge Health, Hawthorn East, Australia, batch number 1063838) at a concentration of $0.044 \mathrm{mg} / \mathrm{mL}$ was employed as this approximated a concentration found in the ELF of patients with sepsis [31].

Amikacin concentrations of $976.1 \mathrm{mg} / \mathrm{L}$ and $410.3 \mathrm{mg} / \mathrm{L}$ were adopted for all experiments, reflecting the median and lower quartile maximum amikacin ELF concentrations, respectively, in a sample of mechanically ventilated patients receiving nebulised amikacin [14]. Amikacin concentrations of $488.1 \mathrm{mg} / \mathrm{L}$ and $205.2 \mathrm{mg} / \mathrm{L}$ were used in Ca-MH broth alone as a control experiment assuming 50\% mucin binding. A growth control was included for each isolate and a combination of ELF milieu variables. Samples were taken at 0, 4, 8, 24, 32 and 48 hours and 0, 24 and 48 hours for quantification on Ca-MH agar and amikacin-supplemented Ca-MH agar, respectively, at a concentration four-fold the baseline isolate MIC. Samples were washed twice in phosphate-buffered saline to minimize antibiotic carry-over, appropriately diluted and plated for quantification. The detection limit was $2-\log _{10} \mathrm{CFU} / \mathrm{mL}$. One replicate was performed for each combination of isolate, amikacin concentration and milieu condition.

\subsection{Pharmacodynamic Modelling}

The pharmacokinetic/pharmacodynamic data of both bacterial isolates were co-modelled using Pmetrics for R Version 1.5.2 based on previously described models of bacterial growth and resistance formation [32,33]. Model parameter abbreviations are in Tables 1 and 2. Model diagnostics including the Akaike information criterion, Bayesian information criterion and coefficient of determination $\left(R^{2}\right)$ from the linear observed vs expected plots were used to evaluate and compare models. 


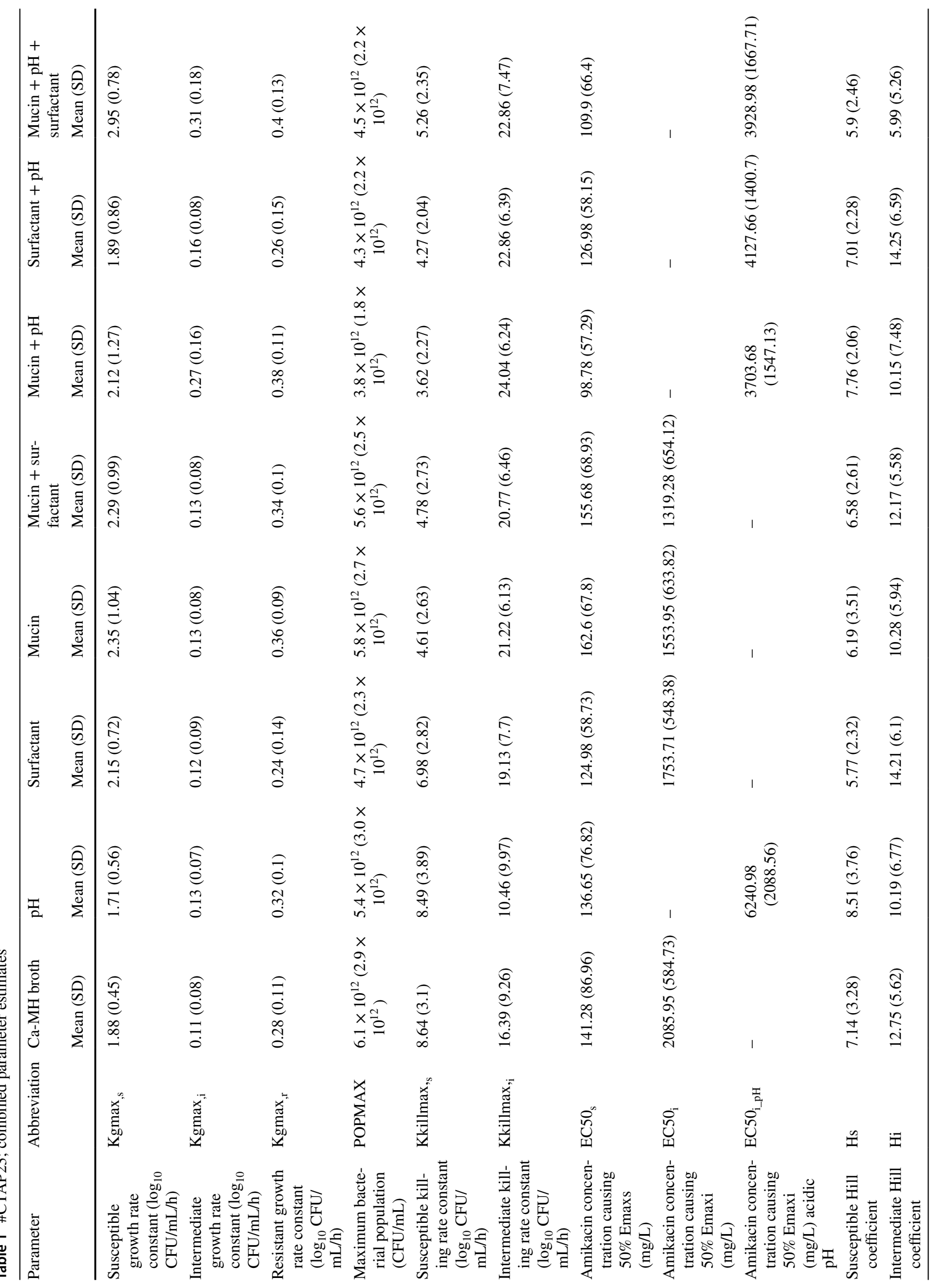




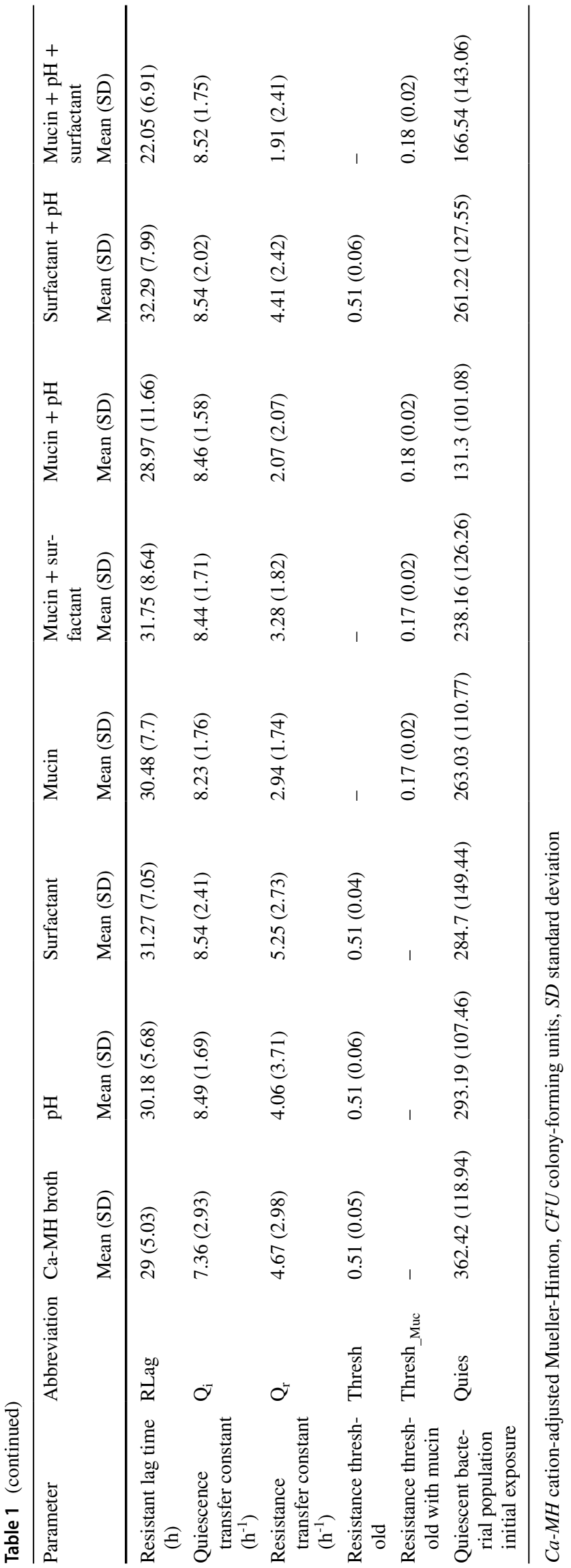

\section{Results}

\subsection{In Vitro Susceptibility Studies}

The modal amikacin MIC was $2 \mathrm{mg} / \mathrm{L}$ and $8 \mathrm{mg} / \mathrm{L}$ for \#CTAP23 and \#CTAP40, respectively.

\subsection{Static Time-Kill Studies}

For all amikacin concentrations against isolates exposed to standard $\mathrm{Ca}-\mathrm{MH}$ broth, there was complete eradication of viable bacterial growth within $24 \mathrm{~h}$, which was sustained for the 48-h experiment duration for the $976.1-\mathrm{mg} / \mathrm{L}$ exposure (Fig. 1; Table 1). Lower amikacin concentrations resulted in some bacterial regrowth from a nadir of no detected viable bacteria at $24 \mathrm{~h}$ to approximate 4-logs of bacterial regrowth, which was also observed on amikacin-containing $\mathrm{Ca}-\mathrm{MH}$ agar (Fig. 2). For both isolates, the addition of an acidic $\mathrm{pH}$ reduced the extent and rate of bacterial killing, with a maximum 7-logs of bacterial killing occurring by $24 \mathrm{~h}$ for both isolates exposed to $976.1 \mathrm{mg} / \mathrm{L}$ and a maximum 3-logs of bacterial killing for both isolates exposed to $410.3 \mathrm{mg} / \mathrm{L}$ (Fig. 1; Table 3). Furthermore, the addition of mucin and an acidic $\mathrm{pH}$ also reduced the rate of bacterial killing for both isolates. After $8 \mathrm{~h}$, there was approximately 7-logs and 2-logs of bacterial killing when exposed to either an acidic $\mathrm{pH}$ or mucin and the combination of the two, respectively, for both isolates in $976.1 \mathrm{mg} / \mathrm{L}$ of amikacin. The bacterial killing was approximately half in the same milieu (approximately 3- to 4-logs of bacterial killing for either an acidic $\mathrm{pH}$ or mucin alone and an approximately 1-log reduction when exposed to both an acidic $\mathrm{pH}$ and mucin) for both isolates in an amikacin concentration of $410.3 \mathrm{mg} / \mathrm{L}$. After $24 \mathrm{~h}$, rapid bacterial re-growth was observed with a corresponding increased growth of bacteria on amikacin-containing $\mathrm{Ca}-\mathrm{MH}$ agar (Fig. 2). However, the rate and extent of regrowth differed between study isolates, with increased regrowth demonstrated by \#CTAP23 (Table 3). Similarly, the combination of mucin and an acidic $\mathrm{pH}$ environment reduced the maximum bacterial killing to 3-logs with a slower rate when compared with the addition of either mucin or an acidic $\mathrm{pH}$. After the total bacterial nadir at approximately $24 \mathrm{~h}$, there was a rapid emergence of bacterial growth on both standard and amikacin-containing Ca-MH agar. The addition of surfactant did not appreciably impact bacterial killing when compared with $\mathrm{Ca}-\mathrm{MH}$ broth alone. No appreciable difference was observed between the growth curves of isolates exposed to mucin, surfactant or an acidic $\mathrm{pH}$ compared with Ca-MH broth alone (Fig. 3). 
Table 2 \#CTAP40; combined parameter estimates

\begin{tabular}{|c|c|c|c|c|c|c|c|c|c|}
\hline Parameter & $\begin{array}{l}\text { Abbrevia- } \\
\text { tion }\end{array}$ & $\begin{array}{l}\text { Ca-MH } \\
\text { broth } \\
\text { Mean (SD) }\end{array}$ & $\begin{array}{l}\mathrm{pH} \\
\text { Mean (SD) }\end{array}$ & $\begin{array}{l}\text { Surfactant } \\
\text { Mean (SD) }\end{array}$ & $\begin{array}{l}\text { Mucin } \\
\text { Mean (SD) }\end{array}$ & $\begin{array}{l}\text { Mucin + } \\
\text { surfactant } \\
\text { Mean (SD) }\end{array}$ & $\begin{array}{l}\text { Mucin + pH } \\
\text { Mean (SD) }\end{array}$ & $\begin{array}{l}\text { Surfactant } \\
+\mathrm{pH} \\
\text { Mean (SD) }\end{array}$ & $\begin{array}{l}\text { Mucin }+\mathrm{pH} \\
+ \text { surfactant } \\
\text { Mean }(\mathrm{SD})\end{array}$ \\
\hline $\begin{array}{l}\text { Susceptible } \\
\text { growth } \\
\text { rate con- } \\
\text { stant }\left(\log _{10}\right. \\
\text { CFU/ } \\
\mathrm{mL} / \mathrm{h})\end{array}$ & $\operatorname{Kgmax}_{, \mathrm{s}}$ & $2.12(0.88)$ & $2.07(1.12)$ & $1.62(0.87)$ & $1.7(0.7)$ & $2.25(1.05)$ & $2.42(1.2)$ & $2.33(1.27)$ & $2.4(1.29)$ \\
\hline $\begin{array}{l}\text { Intermedi- } \\
\text { ate growth } \\
\text { rate con- } \\
\text { stant }\left(\log _{10}\right. \\
\text { CFU/ } \\
\mathrm{mL} / \mathrm{h})\end{array}$ & $\operatorname{Kgmax}_{, i}$ & $0.05(0.07)$ & $0.16(0.11)$ & $0.07(0.09)$ & $0.21(0.07)$ & $0.2(0.1)$ & $0.29(0.14)$ & $0.16(0.07)$ & $0.13(0.09)$ \\
\hline $\begin{array}{l}\text { Resistant } \\
\text { growth } \\
\text { rate con- } \\
\text { stant }\left(\log _{10}\right. \\
\text { CFU/ } \\
\mathrm{mL} / \mathrm{h})\end{array}$ & $\operatorname{Kgmax}_{, \mathrm{r}}$ & $0.26(0.16)$ & $0.22(0.18)$ & $0.35(0.13)$ & $0.12(0.15)$ & $0.26(0.16)$ & $0.41(0.09)$ & $0.37(0.13)$ & $0.37(0.07)$ \\
\hline $\begin{array}{l}\text { Maximum } \\
\text { bacterial } \\
\text { population } \\
(\mathrm{CFU} / \mathrm{mL})\end{array}$ & POPMAX & $\begin{array}{c}4.4 \times 10^{12} \\
(2.5)\end{array}$ & $\begin{array}{c}4.0 \times 10^{12} \\
(3.9 \times \\
\left.10^{12}\right)\end{array}$ & $\begin{array}{c}4.3 \times 10^{12} \\
(3.6 \times \\
\left.10^{12}\right)\end{array}$ & $\begin{array}{c}4.9 \times 10^{12} \\
(1.6 \times \\
\left.10^{12}\right)\end{array}$ & $\begin{array}{c}4.0 \times 10^{12} \\
(3.3 \times \\
\left.10^{12}\right)\end{array}$ & $\begin{array}{c}3.1 \times 10^{12} \\
(2.7 \times \\
\left.10^{12}\right)\end{array}$ & $\begin{array}{c}5.0 \times 10^{12} \\
(3.5 \times \\
\left.10^{12}\right)\end{array}$ & $\begin{array}{l}5.3 \times 10^{12} \\
(4.1 \times \\
\left.10^{12}\right)\end{array}$ \\
\hline $\begin{array}{l}\text { Susceptible } \\
\text { killing rate } \\
\text { constant } \\
\text { ( } \log _{10} \\
\text { CFU/ } \\
\mathrm{mL} / \mathrm{h})\end{array}$ & Kkillmax, & $6.03(2.59)$ & $3.43(1.85)$ & $5.19(3.31)$ & $4.23(2.2)$ & $4.33(2.23)$ & $3.63(2.2)$ & $3.9(1.73)$ & $4.21(2.45)$ \\
\hline $\begin{array}{l}\text { Intermediate } \\
\text { killing rate } \\
\text { constant } \\
\left(\log _{10}\right. \\
\mathrm{CFU} / \\
\mathrm{mL} / \mathrm{h})\end{array}$ & Kkillmax, $_{\mathrm{i}}$ & $20.58(4.68)$ & $15.28(9.07)$ & $20.96(5.98)$ & $12.33(6.85)$ & $21.33(6.15)$ & $26.14(5.72)$ & $21.45(6.31)$ & $23.33(5.89)$ \\
\hline $\begin{array}{l}\text { Amikacin } \\
\text { concentra- } \\
\text { tion caus- } \\
\text { ing 50\% } \\
\text { Emaxs } \\
(\mathrm{mg} / \mathrm{L})\end{array}$ & $\mathrm{EC} 50_{\mathrm{s}}$ & $\begin{array}{l}126.81 \\
(61.38)\end{array}$ & $\begin{array}{l}165.45 \\
(61.83)\end{array}$ & $\begin{array}{l}136.23 \\
(59.12)\end{array}$ & $\begin{array}{l}178.13 \\
(64.06)\end{array}$ & $\begin{array}{l}134.31 \\
(84.72)\end{array}$ & $\begin{array}{l}129.39 \\
(69.48)\end{array}$ & $\begin{array}{l}180.63 \\
(73.51)\end{array}$ & $\begin{array}{l}169.63 \\
(63.13)\end{array}$ \\
\hline $\begin{array}{l}\text { Amikacin } \\
\text { concentra- } \\
\text { tion caus- } \\
\text { ing 50\% } \\
\text { Emaxi } \\
(\mathrm{mg} / \mathrm{L})\end{array}$ & $\mathrm{EC} 50_{\mathrm{i}}$ & $\begin{array}{r}1940.22 \\
(602.8)\end{array}$ & - & $\begin{array}{l}1728.19 \\
(708.66)\end{array}$ & $\begin{array}{l}1353.81 \\
\quad(408.55)\end{array}$ & $\begin{array}{l}1562.25 \\
(435.98)\end{array}$ & - & - & - \\
\hline $\begin{array}{l}\text { Amikacin } \\
\text { concentra- } \\
\text { tion caus- } \\
\text { ing } 50 \% \\
\text { Emaxi } \\
(\mathrm{mg} / \mathrm{L}) \\
\text { acidic } \mathrm{pH}\end{array}$ & $\mathrm{EC} 50_{\mathrm{i} \_\mathrm{pH}}$ & - & $\begin{array}{l}3818.05 \\
\quad(1480.55)\end{array}$ & - & - & - & $\begin{array}{l}4220.81 \\
\quad(1329.18)\end{array}$ & $\begin{array}{l}4228.27 \\
\quad(1288.75)\end{array}$ & $\begin{array}{l}4513 \\
\quad(1266.74)\end{array}$ \\
\hline $\begin{array}{l}\text { Susceptible } \\
\text { Hill coef- } \\
\text { ficient }\end{array}$ & Hs & $5.32(2.04)$ & $7.13(3.43)$ & $7.24(2.34)$ & $9.09(2.52)$ & $7.66(3.14)$ & $7.7(2.48)$ & $6.22(3.61)$ & $6.78(4.56)$ \\
\hline
\end{tabular}


Table 2 (continued)

\begin{tabular}{|c|c|c|c|c|c|c|c|c|c|}
\hline Parameter & $\begin{array}{l}\text { Abbrevia- } \\
\text { tion }\end{array}$ & $\begin{array}{l}\text { Ca-MH } \\
\text { broth } \\
\text { Mean (SD) }\end{array}$ & $\begin{array}{l}\mathrm{pH} \\
\text { Mean (SD) }\end{array}$ & $\begin{array}{l}\text { Surfactant } \\
\text { Mean (SD) }\end{array}$ & $\begin{array}{l}\text { Mucin } \\
\text { Mean (SD) }\end{array}$ & $\begin{array}{l}\text { Mucin + } \\
\text { surfactant } \\
\text { Mean (SD) }\end{array}$ & $\begin{array}{l}\text { Mucin + pH } \\
\text { Mean (SD) }\end{array}$ & $\begin{array}{l}\text { Surfactant } \\
+\mathrm{pH} \\
\text { Mean (SD) }\end{array}$ & $\begin{array}{l}\text { Mucin + pH } \\
+ \text { surfactant } \\
\text { Mean (SD) }\end{array}$ \\
\hline $\begin{array}{l}\text { Intermediate } \\
\text { Hill coef- } \\
\text { ficient }\end{array}$ & $\mathrm{Hi}$ & $14.95(4.61)$ & $4.91(3.81)$ & 8.18 (2.59) & $5.48(4.14)$ & $6.69(4.05)$ & $4.05(3.25)$ & $6.41(3.37)$ & $5.26(3.39)$ \\
\hline $\begin{array}{l}\text { Resistant lag } \\
\text { time (h) }\end{array}$ & RLag & $32.8(6.52)$ & $24.2(6.7)$ & $36.34(5.19)$ & $22.92(5.18)$ & $\begin{array}{l}24.06 \\
\quad(10.19)\end{array}$ & $25.72(8.3)$ & $28.62(6.86)$ & $28.81(5.92)$ \\
\hline $\begin{array}{l}\text { Quiescence } \\
\text { transfer } \\
\text { constant } \\
\left(\mathrm{h}^{-1}\right)\end{array}$ & $\mathrm{Q}_{\mathrm{i}}$ & $8.04(2.5)$ & $5.33(3.57)$ & $8.03(1.95)$ & $3.89(3.42)$ & $7.71(2.02)$ & 9.05 (1.33) & $8.32(2.41)$ & $7.21(1.66)$ \\
\hline $\begin{array}{l}\text { Resistance } \\
\text { transfer } \\
\text { constant } \\
\left(\mathrm{h}^{-1}\right)\end{array}$ & $\mathrm{Q}_{\mathrm{r}}$ & $4.01(1.77)$ & $2.88(1.46)$ & $4.67(2.63)$ & $6.79(2.66)$ & $3.29(1.46)$ & $1.34(1.26)$ & $2.49(1.54)$ & $2.22(1.12)$ \\
\hline $\begin{array}{l}\text { Resistance } \\
\text { threshold }\end{array}$ & Thresh & $0.51(0.05)$ & $0.52(0.07)$ & $0.54(0.09)$ & - & - & - & $0.55(0.1)$ & - \\
\hline $\begin{array}{l}\text { Resistance } \\
\text { thresh- } \\
\text { old with } \\
\text { mucin }\end{array}$ & Thresh_Muc $_{\text {_M }}$ & - & - & - & $0.17(0.01)$ & $0.18(0.02)$ & $0.19(0.02)$ & - & $0.17(0.03)$ \\
\hline $\begin{array}{l}\text { Quiescent } \\
\text { bacterial } \\
\text { popula- } \\
\text { tion initial } \\
\text { exposure }\end{array}$ & Quies & $\begin{array}{l}199.54 \\
(168.71)\end{array}$ & $\begin{array}{l}295.35 \\
(69.93)\end{array}$ & $\begin{array}{l}246.68 \\
(196.69)\end{array}$ & $\begin{array}{l}133.44 \\
(123.66)\end{array}$ & $\begin{array}{l}267.8 \\
\quad(87.22)\end{array}$ & $\begin{array}{l}223.05 \\
\quad(123.94)\end{array}$ & $\begin{array}{l}269.98 \\
(72.37)\end{array}$ & $\begin{array}{l}312.32 \\
\quad(76.81)\end{array}$ \\
\hline
\end{tabular}

$C F U$ colony-forming units, $\mathrm{Ca}-\mathrm{MH}$ cation-adjusted Mueller-Hinton, $S D$ standard deviation

(A) \#CTAP40

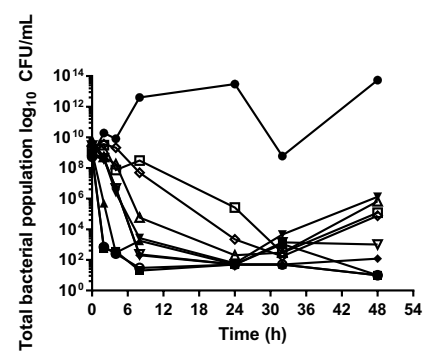

(B) \#CTAP40

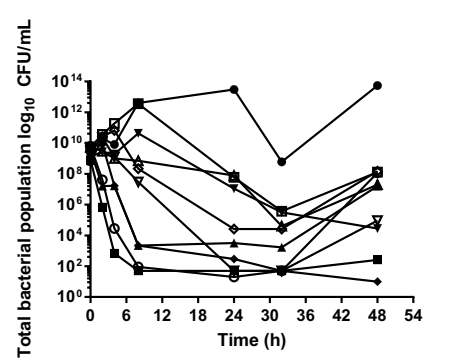

- Ca-MH Broth only

- Amk $976.1 \mathrm{mg} / \mathrm{L}$

- Amk $488.05 \mathrm{mg} / \mathrm{L}$

- Amk $976.1 \mathrm{mg} / \mathrm{L}+\mathrm{pH}$

$\rightarrow$ Amk $976.1 \mathrm{mg} / \mathrm{L}+$ Mucin

— Amk $976.1 \mathrm{mg} / \mathrm{L}+$ Surfactant

廿 Amk $976.1 \mathrm{mg} / \mathrm{L}+$ Mucin $+\mathrm{pH}$

$\triangle$ Amk $976.1 \mathrm{mg} / \mathrm{L}+$ Surfactant $+\mathrm{pH}$

₹ Amk $976.1 \mathrm{mg} / \mathrm{L}+$ Mucin + Surfactant

$\multimap$ Amk $976.1 \mathrm{mg} / \mathrm{L}+$ Mucin + Surfactant + pH
(C) \#CTAP23

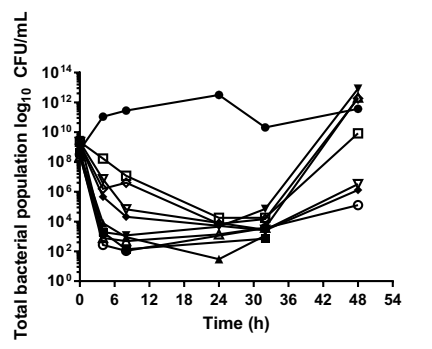

$\rightarrow$ Ca-MH Broth only

- Amk $976.1 \mathrm{mg} / \mathrm{L}$

- Amk $488.05 \mathrm{mg} / \mathrm{L}$

- Amk $976.1 \mathrm{mg} / \mathrm{L}+\mathrm{pH}$

$\rightarrow$ Amk $976.1 \mathrm{mg} / \mathrm{L}+$ Mucin

— Amk $976.1 \mathrm{mg} / \mathrm{L}+$ Surfactant

— Amk $976.1 \mathrm{mg} / \mathrm{L}+$ Mucin $+\mathrm{pH}$

$\triangle$ Amk $976.1 \mathrm{mg} / \mathrm{L}+$ Surfactant $+\mathrm{pH}$

₹ Amk $976.1 \mathrm{mg} / \mathrm{L}+$ Mucin + Surfactant

— Amk $976.1 \mathrm{mg} / \mathrm{L}+$ Mucin + Surfactant + pH
(D) \#CTAP23

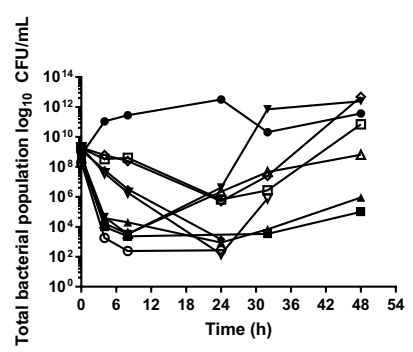

$\rightarrow$ Ca-MH Broth only

- Amk $410.3 \mathrm{mg} / \mathrm{L}$

- Amk $205.15 \mathrm{mg} / \mathrm{L}$

- Amk $410.3 \mathrm{mg} / \mathrm{L}+\mathrm{pH}$

$\rightarrow$ Amk $410.3 \mathrm{mg} / \mathrm{L}+$ Mucin

— Amk $410.3 \mathrm{mg} / \mathrm{L}+$ Surfactant

— Amk $410.3 \mathrm{mg} / \mathrm{L}+$ Mucin $+\mathrm{pH}$

屯 Amk $410.3 \mathrm{mg} / \mathrm{L}+$ Surfactant $+\mathrm{pH}$

$\rightarrow$ Amk $410.3 \mathrm{mg} / \mathrm{L}+$ Mucin + Surfactant

- Amk $410.3 \mathrm{mg} / \mathrm{L}+$ Mucin + Surfactant + pH

Fig. 1 Total bacterial killing curves for amikacin (Amk) in simulated epithelial lining fluid milieu. a \#CTAP40 976.1 mg/L; b \#CTAP40 410.3 $\mathrm{mg} / \mathrm{L}$; $\mathbf{c}$ \#CTAP23 976.1 mg/L, d \#CTAP23 $410.3 \mathrm{mg} / \mathrm{L}$. CFU colony-forming units 

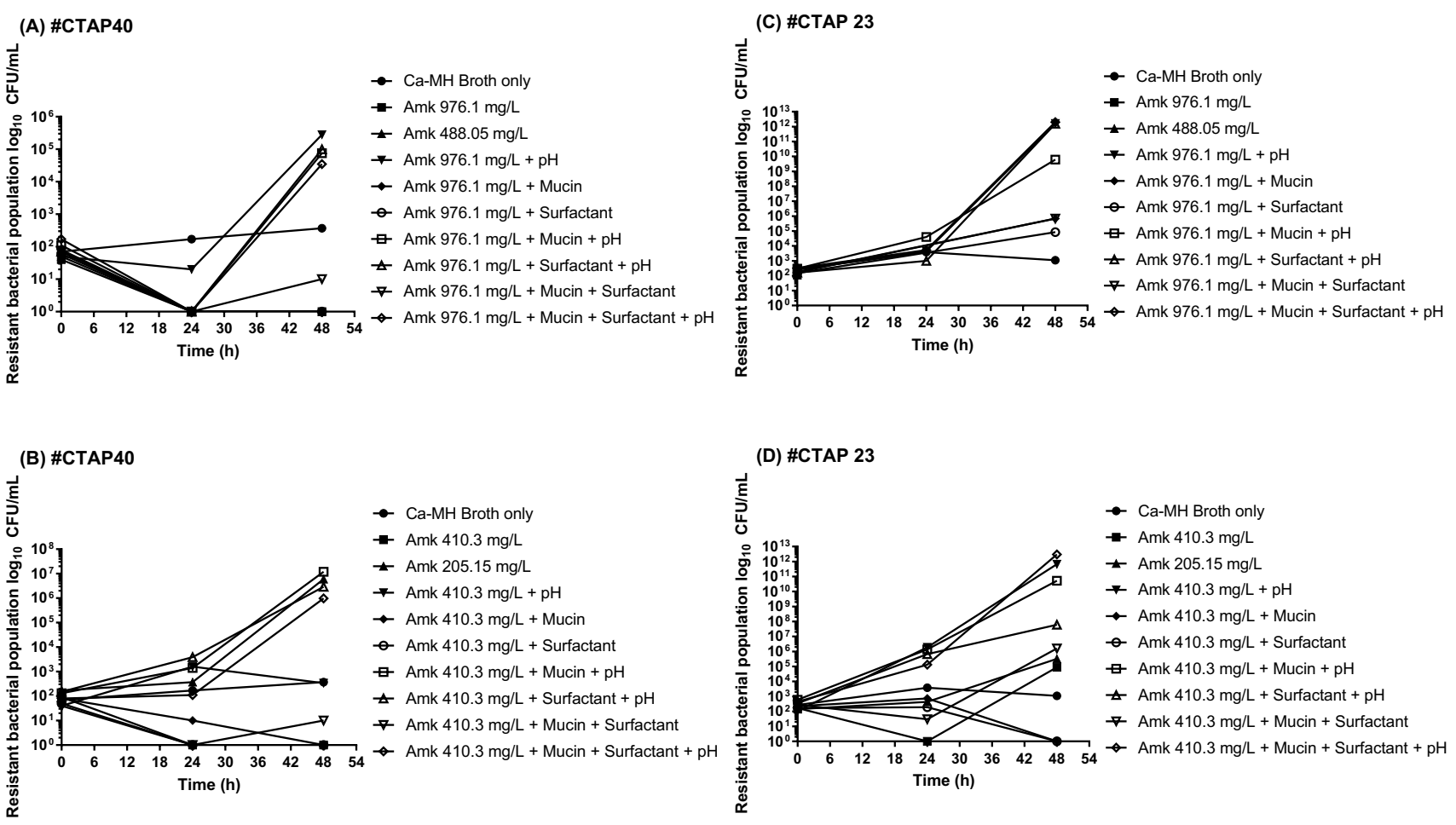

Fig. 2 Resistant bacterial killing curves for amikacin (Amk) in simulated epithelial lining fluid milieu. a \#CTAP40 976.1 mg/L; b \#CTAP40 $410.3 \mathrm{mg} / \mathrm{L}$; c \#CTAP23 976.1 mg/L, d \#CTAP23 $410.3 \mathrm{mg} / \mathrm{L}$. CFU colony-forming units

Table 3 Change in bacterial kill $(\log 10 \mathrm{CFU} / \mathrm{mL})$ for both isolates exposed to amikacin at a concentration of 976.1 and $410.3 \mathrm{mg} / \mathrm{L}$

\begin{tabular}{|c|c|c|c|c|c|c|c|c|}
\hline \multirow[t]{3}{*}{ Condition } & \multicolumn{4}{|c|}{ Amikacin $976.1 \mathrm{mg} / \mathrm{L}$} & \multicolumn{4}{|c|}{ Amikacin $410.3 \mathrm{mg} / \mathrm{L}$} \\
\hline & \multicolumn{2}{|c|}{ \#CTAP40 } & \multicolumn{2}{|c|}{ \#CTAP23 } & \multicolumn{2}{|c|}{ \#CTAP40 } & \multicolumn{2}{|c|}{ \#CTAP23 } \\
\hline & $24 \mathrm{~h}$ & $48 \mathrm{~h}$ & $24 \mathrm{~h}$ & $48 \mathrm{~h}$ & $24 \mathrm{~h}$ & $48 \mathrm{~h}$ & $24 \mathrm{~h}$ & $48 \mathrm{~h}$ \\
\hline Broth only & -7.16 & -7.86 & -8.61 & -8.61 & -7.19 & -6.48 & -8.66 & -3.66 \\
\hline Broth $+\mathrm{pH}$ & -7.19 & -2.85 & -5.80 & 3.46 & -2.08 & -4.67 & -2.09 & 3.67 \\
\hline Broth + mucin & -7.11 & -6.73 & -9.17 & -3.05 & -7.29 & -8.75 & -5.96 & -9.11 \\
\hline Broth + surfactant & -7.03 & -7.73 & -8.51 & -3.40 & -8.49 & -1.72 & -5.87 & -8.30 \\
\hline Broth + mucin $+\mathrm{pH}$ & -3.70 & -4.03 & -5.10 & 0.57 & -1.95 & -1.62 & -3.42 & 1.59 \\
\hline Broth + surfactant $+\mathrm{pH}$ & -7.43 & -3.91 & -5.25 & 3.93 & -1.85 & -2.45 & -1.98 & 0.49 \\
\hline Broth + mucin + surfactant & -7.76 & -6.46 & -9.33 & -2.82 & -7.83 & -4.56 & -7.14 & -9.32 \\
\hline Broth + mucin + surfactant $+\mathrm{pH}$ & -6.10 & -4.57 & -5.36 & 3.07 & -5.00 & -1.24 & -3.58 & 3.39 \\
\hline
\end{tabular}

$C F U$ colony-forming units, $h$ hours

\subsection{Pharmacodynamic Modelling}

Our pharmacodynamic model is represented by Eqs. (1-4) that detail the growth and killing characteristics of the susceptible, intermediate and resistant bacterial populations, as well as the change in the quiescent bacterial population. Susceptible and intermediate bacterial populations were best described by incorporating amikacin-mediated bacterial killing and de novo emergence of resistance from a quiescent bacterial population. The formation of a quiescent population was facilitated by a transfer from the susceptible and intermediate subpopulations $(\mathrm{Qi})$ when a threshold bacterial density was reached, which was modelled as a parameter (Thresh) multiplied by the population maximum. There was no transfer from the susceptible or intermediate bacterial compartments to the quiescent state before the threshold bacterial density was reached. This value was separated into two variables, one derived from experimental conditions with mucin and another including experimental conditions excluding mucin. The initial bacterial density of the 
Fig. 3 Bacterial growth curves in different simulated epithelial lining fluid environments for \#CTAP40 (a) and \#CTAP23 (b). $C F U$ colony-forming units
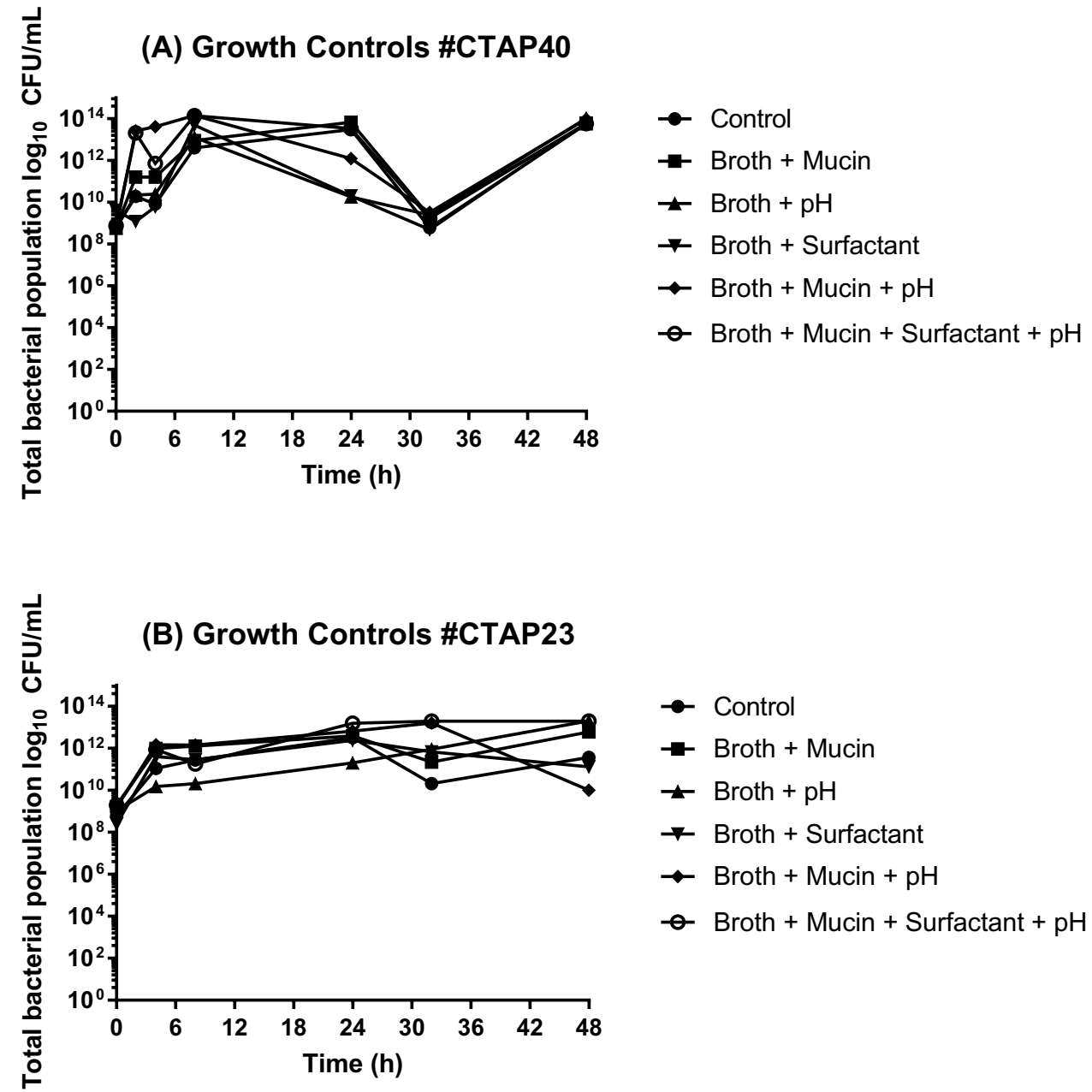

quiescent (Quies; Tables 1 and 2) population was estimated. The resistant lag time (RLag; Tables 1 and 2) represents the estimated lead time taken before bacteria are able to transfer from the quiescent population state to the resistant state. The amikacin concentration achieving $50 \%$ of the maximal bacterial killing for the intermediate bacterial subpopulation (EC50i) was separated into two variables, one derived from the presence of an acidic $\mathrm{pH}$ and another derived from experimental conditions without an acidic $\mathrm{pH}$.

The model was able to describe the bacterial killing and emergence of amikacin resistance in the presence of mucin, surfactant and an acidic $\mathrm{pH}$. Posterior $R^{2}$ estimates were 0.819 and 0.906 for the total bacterial population and the combination of resistant and intermediate susceptibility isolates, respectively (Figs. 4 and 5 for the total bacterial population and intermediate/resistant population, respectively). Incorporating the $\mathrm{pH}$ and mucin as covariates improved the Akaike information criterion by 5.6 and improved the observed vs predicted plots. Conditions including an acidic $\mathrm{pH}$ and mucin had an appreciable reduction in the onset of resistance emergence and a reduced threshold for the onset of bacterial transfer to a quiescent state (Tables 1 and 2).

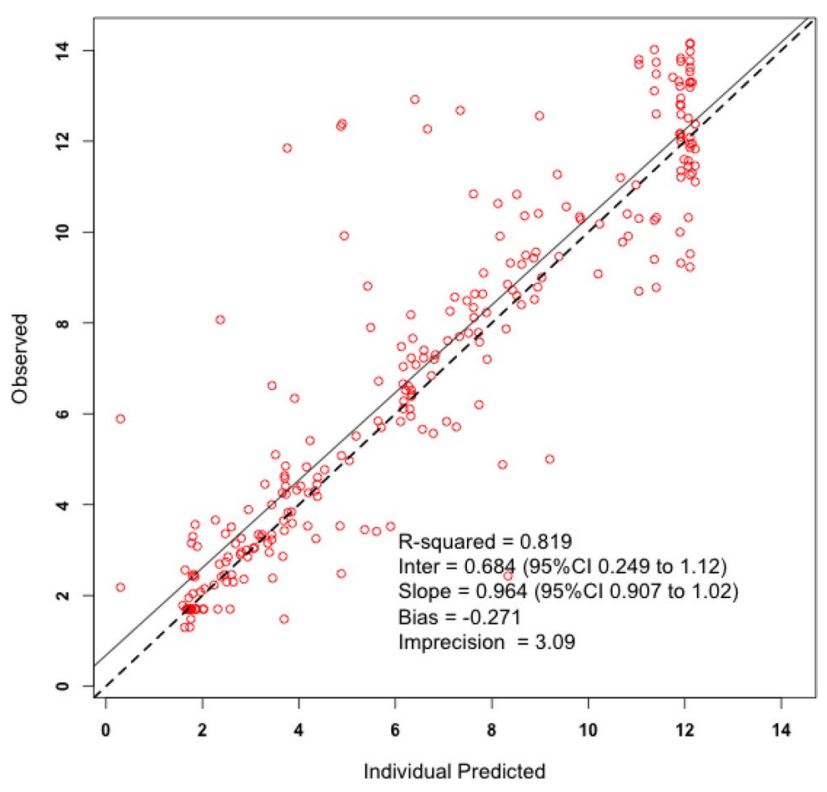

Fig. 4 Observed vs predicted plot of the posterior model estimates for the total bacterial population. $C I$ confidence interval 


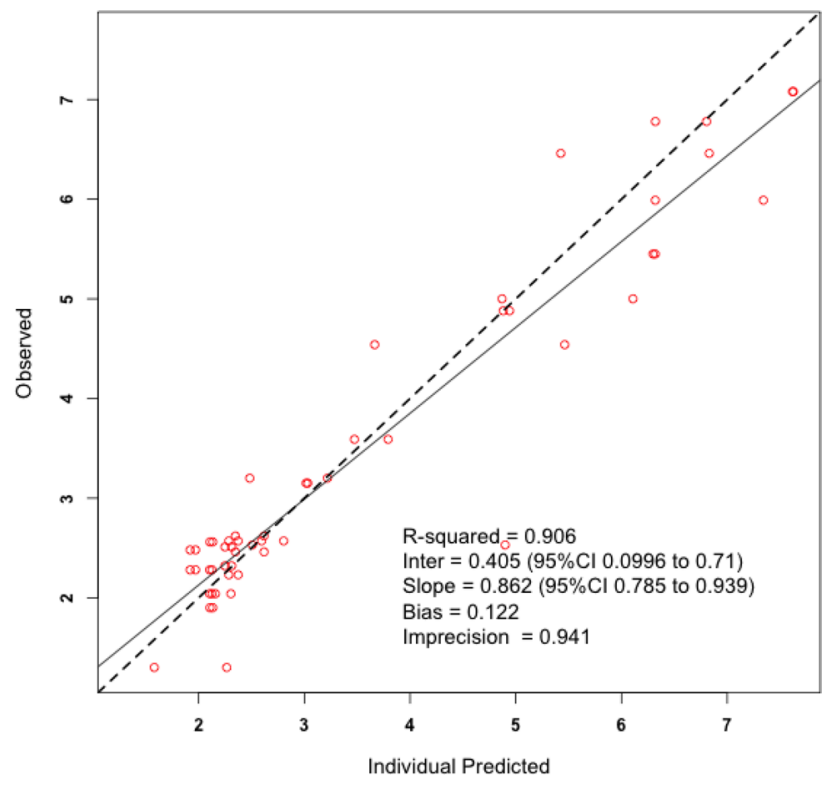

Fig. 5 Observed vs predicted plot of the posterior model estimates for the intermediate and resistant bacterial subpopulations. $C I$ confidence interval

Moreover, an acidic $\mathrm{pH}$ appreciably increased the EC50i, reducing the bacterial killing of the intermediate subpopulation. The final model visual predictive checks are available in Figs. 1 (total bacterial population) and 2 (resistant and intermediate bacterial population) of the Electronic Supplementary Material.

$$
\begin{aligned}
\frac{\mathrm{dCFUs}}{\mathrm{d} t}= & K_{\mathrm{gmax}, s} \times \mathrm{CFUs} \times\left(1-\frac{\mathrm{CFUs}+\mathrm{CFUi}+\mathrm{CFUr}+\mathrm{CFUq}}{\mathrm{POPMAX}}\right) \\
& -\mathrm{CFUs} \times K_{\mathrm{killmax}, s} \times\left(\frac{\mathrm{AMK}^{\mathrm{Hs}}}{\mathrm{EC}^{\mathrm{Hs}} 0_{s}^{\mathrm{Hs}}+\mathrm{AMK}^{\mathrm{Hs}}}\right)-\mathrm{Qi} \times \mathrm{CFUs}
\end{aligned}
$$

$$
\begin{aligned}
\frac{\mathrm{dCFUi}}{\mathrm{d} t}= & K_{\mathrm{gmax}, i} \times \mathrm{CFUi} \times\left(1-\frac{\mathrm{CFUs}+\mathrm{CFUi}+\mathrm{CFUr}+\mathrm{CFUq}}{\mathrm{POPMAX}}\right) \\
& -\mathrm{CFUi} \times K_{\mathrm{killmax}, i} \times\left(\frac{\mathrm{AMK}^{\mathrm{Hi}}}{\mathrm{EC}^{\mathrm{Hi}}{ }_{i}^{\mathrm{Hi}}+\mathrm{AMK}^{\mathrm{Hi}}}\right)-\mathrm{Qi} \times \mathrm{CFUi}
\end{aligned}
$$

$$
\begin{aligned}
\frac{\mathrm{dCFUr}}{\mathrm{d} t}= & K_{\mathrm{gmax}, r} \times \mathrm{CFUr} \\
& \times\left(1-\frac{\mathrm{CFUs}+\mathrm{CFUi}+\mathrm{CFUr}+\mathrm{CFUq}}{\text { POPMAX }}\right)+\mathrm{Qr} \times \mathrm{CFUq}
\end{aligned}
$$

$$
\frac{\mathrm{dCFUq}}{\mathrm{d} t}=\mathrm{Qi} \times(\mathrm{CFUs}+\mathrm{CFUi})-\mathrm{Qr} \times \mathrm{CFUq}
$$

where CFUi are $\log _{10}$ colony-forming units $/ \mathrm{mL}$ of the intermediate bacterial population, CFUq are the $\log _{10}$ colonyforming units/mL of the quiescent bacterial subpopulation, CFUr are $\log _{10}$ colony-forming units $/ \mathrm{mL}$ of the resistant bacterial subpopulation, CFUs are $\log _{10}$ colony-forming units $/ \mathrm{mL}$ of the susceptible bacterial population, EC50i is the amikacin concentration causing 50\% Emaxi (mg/L), EC50s is the amikacin concentration causing 50\% Emaxs $(\mathrm{mg} / \mathrm{L}), H i$ is the Hill constant for the intermediate bacterial population, $H s$ is the Hill constant for the susceptible bacterial population, Kgmax,/ is the growth rate constant of the intermediate bacterial population $\log _{10} \mathrm{CFU} / \mathrm{mL} / \mathrm{h}, \mathrm{Kgmax}$,/ is the growth rate constant of the resistant bacterial population $\log _{10} \mathrm{CFU} / \mathrm{mL} / \mathrm{h}, \mathrm{Kgmax}, s$ is the growth rate constant of the susceptible bacterial population $\log _{10} \mathrm{CFU} / \mathrm{mL} / \mathrm{h}$, Kkillmax, $s$ is the maximum amikacin bacterial killing rate constant for the susceptible bacterial population $\log _{10} \mathrm{CFU} /$ $\mathrm{mL} / \mathrm{h}$, Kkillmax, $I$ is the maximum amikacin bacterial killing rate constant for the intermediate population $\log _{10} \mathrm{CFU} /$ $\mathrm{mL} / \mathrm{h}$, POPMAX is the maximum bacterial population CFU/ $\mathrm{mL}, \mathrm{Qi}$ is the rate transfer constant from the susceptible and intermediate bacterial populations to the quiescent bacterial population that was activated after a bacterial threshold was reached, which was altered by the presence of mucin $\mathrm{h}^{-1}$, and Qr is the rate transfer constant from the quiescent bacterial population to the resistant bacterial population $\mathrm{h}^{-1}$.

\section{Discussion}

Our data support the hypothesis that the ELF antagonises bacterial killing of amikacin and amplifies emerging $P$. aeruginosa resistance. Importantly, this antagonism is observed at the high ELF amikacin concentrations that are achieved following inhalational delivery.

Our study results are consistent with the published data. A previous in vitro study investigated the impact of mucin on the tobramycin MIC against several bacterial species. [22]. Consistently, the addition of porcine mucin $2 \%$ increased the MIC up to 64-fold, which was attributed to the reduction in the free unbound tobramycin concentrations resulting from mucin binding [22]. Similarly, we identified an appreciable reduction in the rate, but not extent of bacterial killing by amikacin at a concentration of either $976.1 \mathrm{mg} / \mathrm{L}$ or $410.3 \mathrm{mg} / \mathrm{L}$ when mucin was added, compared with 488.1 $\mathrm{mg} / \mathrm{L}$ or $205.2 \mathrm{mg} / \mathrm{L}$ in Ca-MH broth alone. A potential reason for the lack of a difference in the total bacterial killing over $24 \mathrm{~h}$ is the high amikacin concentrations used in our study, relative to the lower concentrations used in the mucin MIC experiments with tobramycin [22]. These factors, in addition to the lack of an identified difference in bacterial killing model parameters, would suggest that the effect of mucin may be multifactorial by promoting $P$. aeruginosa biofilm formation, thereby contributing to the emergence of amikacin resistance and reducing the rate of bacterial killing $[34,35]$. It is likely that the effect of mucin extends beyond reducing the unbound fraction, given the difference in resistance emergence and bacterial killing and the similar 
bacterial killing curves for a 976.1-mg/L and 488.05-mg/L amikacin concentration when exposed to broth alone. Additionally, bacterial killing was most impaired when mucin and an acidic milieu were combined, potentially suggesting an interaction effect whereby a reduction in $\mathrm{pH}$ induces a mucin state change. Another possible mechanism of mucin is inducing adaptive resistance, which was not identified in our study [36]. Additionally, the bacterial regrowth appeared to be increased at $48 \mathrm{~h}$ for \#CTAP23 (MIC $2 \mathrm{mg} / \mathrm{L}$ ) compared with \#CTAP40 (MIC $8 \mathrm{mg} / \mathrm{L}$ ), which may highlight a differential response between isolates to the selective pressure of amikacin and the ELF milieu.

The acidic ELF environment, in combination with mucin, further reduces the rate and extent of bacterial killing. However, this effect may be reversible. Introducing an alkaline media by adding L-arginine can restore aminoglycoside bacterial killing and inhibit biofilm formation, which warrants further examination [37]. Similar to mucin, studies have identified that surfactant at a concentration of $25 \mathrm{mg} / \mathrm{mL}$ can also antagonise tobramycin [23]. This contrasts with our study, which used a lower, physiologically appropriate surfactant concentration of $44 \mu \mathrm{g} / \mathrm{mL}$, and we failed to identify an appreciable difference in bacterial killing or emerging resistance compared with CA-MH broth alone [31].

Patients prescribed aminoglycosides as monotherapy for pneumonia have reduced clinical cure rates compared with other sites of infection, such as the urinary tract [38, 39]. In addition to the reduced ELF: plasma penetration of amikacin following intravenous administration, the ELF inhibits aminoglycoside-mediated bacterial killing and suppresses neutrophil-mediated phagocytosis and bacterial eradication [40]. Therefore, the ability of intravenous aminoglycoside monotherapy to reduce the bacterial burden to below $1 \times 10^{6}$ $\mathrm{CFU} / \mathrm{mL}$, a threshold associated with maximal granulocyte bacterial clearance, is likely low and may only be possible in patients achieving the maximal possible aminoglycoside exposure following nebulised therapy [29]. Furthermore, amplifying less-susceptible bacterial subpopulations identified in this study when bacteria were exposed to an acidic $\mathrm{pH}$ and to mucins highlights the importance of the ELF contributing to antibiotic resistance developing in patients with P. aeruginosa VAP [41]. In a small study (314 patients), 18\% of those with recurrent VAP had amikacin-resistant isolates when this antibiotic was used to treat the original infection [41]. Taken together, it is likely that inhibition of both amikacin- and granulocyte-mediated bacterial killing by the ELF substantially contributes to the failure of previous clinical trials to demonstrate a clinical benefit from adding inhaled amikacin to standard VAP antibiotic management.

Nevertheless, our study has several limitations. First, a range of mucin concentrations has been used previously in similar studies; however, no study has yet reported the actual mucin concentration range in patients with VAP [21, 22, 30]. Therefore, it is likely that other mucin concentrations may exist in vivo and indeed in different lung anatomical compartments. Second, we did not simulate the full amikacin concentration-time curve that may occur following nebulised administration and the inter-patient variability in the concentration-time curve within the ELF following inhalation [14]. However, we simulated the expected $C_{\max }$, which would likely provide the maximum bacterial killing, but may also alter the propensity for antibiotic resistance emergence relative to the short duration of time the $C_{\max }$ would be achieved in vivo [42]. Third, we did not replicate the dynamic movement of mucin secretion and clearance as would occur in vivo. Fourth, porcine mucin was used that may have increased sulfation in composition to that found in human patients leading to an increased negative charge [43]; however, the core mucin structures are shared between porcine and human mucin $[44,45]$. Fifth, we did not examine the effect of positively charged extra-cellular DNA in ELF upon amikacin activity, although prior studies suggest this would be minimal [30]. Sixth, we did not account for the effect of the host immune response for bacterial killing. Seventh, porcine surfactant was used to simulate the ELF environment, which differs in composition to human surfactant with less neutral lipids and reduced concentrations of surfactant proteins A-D, most notably A and D [46]. Last, we only assessed the effect of the ELF on two P. aeruginosa isolates with a single set of experiments. This key limitation should be addressed with future studies with a representative sample of MICs and clinical isolates. Moreover, a lack of replicates may be a cause for the lack of an appreciable difference in some mean model parameter estimates given the significant heterogeneity that exists between the ELF milieu parameters and isolates used.

\section{Conclusions}

We found that simulated ELF conditions inhibit the bacterial killing of even susceptible $P$. aeruginosa isolates and amplify antibiotic resistance developing to aminoglycosides, such as amikacin. Although based on a small number of clinical isolates, and additional studies are required, these results provide an insight into the difficulties faced when relying upon aminoglycosides to treat VAP caused by both susceptible and multi-drug resistant Gram-negative bacilli. They also support calls for the development of new antibiotic formulations to optimise bacterial killing and prevent the emergence of antibiotic resistance in pathogens responsible for this severe and difficult-to-treat hospital-acquired infection. 
Supplementary Information The online version contains supplementary material available at https://doi.org/10.1007/s40268-021-00344-5.

\section{Declarations}

Funding AJH would like to acknowledge funding from a Griffith School of Medicine Research Higher degree scholarship. FBS is funded in part by the NHMRC Investigator Grant (APP1197866). SMSL acknowledges funding from the University of Queensland Research Training Scholarship. JAR is funded in part by a Practitioner Fellowship (APP1117065) from the NHMRC.

Conflicts of Interest/Competing Interests Aaron J. Heffernan, Fekade B. Sime, Sazlyna Mohd Sazlly Lim, Saiyuri Naicker, Katherine T. Andrews, David Ellwood, Jeffrey Lipman, Keith Grimwood and Jason A. Roberts have no conflicts of interest that are directly relevant to the content of this article.

Ethics approval Ethics approval is not required for this in vitro bacterial cell experiment. No human data was used for this publication.

Consent to Participate Not applicable.

Consent for Publication No human data was used for this publication. All authors consent to publication of this manuscript.

Availability of Data and Material Not available.

Code Availability Available on reasonable request.

Authors' Contributions All authors contributed to the study conception and design. Material preparation, data collection and analysis were performed by AH, FS, SN, SMSL and JR. The first draft was prepared by $\mathrm{AH}$. All authors made significant contributions to the manuscript development and approved the final manuscript.

Open Access This article is licensed under a Creative Commons Attribution-NonCommercial 4.0 International License, which permits any non-commercial use, sharing, adaptation, distribution and reproduction in any medium or format, as long as you give appropriate credit to the original author(s) and the source, provide a link to the Creative Commons licence, and indicate if changes were made. The images or other third party material in this article are included in the article's Creative Commons licence, unless indicated otherwise in a credit line to the material. If material is not included in the article's Creative Commons licence and your intended use is not permitted by statutory regulation or exceeds the permitted use, you will need to obtain permission directly from the copyright holder. To view a copy of this licence, visit http://creativecommons.org/licenses/by-nc/4.0/.

\section{References}

1. Elliott D, Elliott R, Burrell A, Harrigan P, Murgo M, Rolls K, et al. Incidence of ventilator-associated pneumonia in Australasian intensive care units: use of a consensus-developed clinical surveillance checklist in a multisite prospective audit. BMJ Open. 2015;5:e08924.

2. Melsen WG, Rovers MM, Groenwold RHH, Bergmans D, Camus C, Bauer TT, et al. Attributable mortality of ventilator-associated pneumonia: a meta-analysis of individual patient data from randomised prevention studies. Lancet Infect Dis. 2013;13:665-71.
3. Scaglione F, Esposito S, Leone S, Lucini V, Pannacci M, Ma L, et al. Feedback dose alteration significantly affects probability of pathogen eradication in nosocomial pneumonia. Eur Respir J. 2009;34:394-400.

4. Nicasio AM, Eagye KJ, Nicolau DP, Shore E, Palter M, Pepe J, et al. Pharmacodynamic-based clinical pathway for empiric antibiotic choice in patients with ventilator-associated pneumonia. $\mathbf{J}$ Crit Care. 2010;25:69-77.

5. Kalil AC, Metersky ML, Klompas M, Muscedere J, Sweeney DA, Palmer LB, et al. Management of adults with hospital-acquired and ventilator-associated pneumonia: 2016 clinical practice guidelines by the Infectious Diseases Society of America and the American Thoracic Society. Clin Infect Dis. 2016;63:575-82.

6. Kiem S, Schentag JJ. Interpretation of antibiotic concentration ratios measured in epithelial lining fluid. Antimicrob Agents Chemother. 2008;52:24-36.

7. Najmeddin F, Shahrami B, Azadbakht S, Dianatkhah M, Rouini MR, Najafi A, et al. Evaluation of epithelial lining fluid concentration of amikacin in critically ill patients with ventilator-associated pneumonia. J Intensive Care Med. 2020;35(4):400-4.

8. Moore RD, Lietman PS, Smith CR. Clinical response to aminoglycoside therapy: importance of the ratio of peak concentration to minimal inhibitory concentration. J Infect Dis. 1987;155:93-9.

9. Kashuba ADM, Nafziger AN, Drusano GL, Bertino JS. Optimizing aminoglycoside therapy for nosocomial pneumonia caused by Gram-negative bacteria. Antimicrob Agents Chemother. 1999;43:623-9.

10. Shortridge D, Gales AC, Streit JM, Huband MD, Tsakris A, Jones RN. Geographic and temporal patterns of antimicrobial resistance in Pseudomonas aeruginosa over 20 years from the SENTRY Antimicrobial Surveillance Program, 1997-2016. Open Forum Infect Dis. 2019;6(Suppl. 1):S63-8.

11. Weiner LM, Webb AK, Limbago B, Dudeck MA, Patel J, Kallen AJ, et al. Antimicrobial-resistant pathogens associated with healthcare-associated infections: summary of data reported to the National Healthcare Safety Network at the Centers for Disease Control and Prevention, 2011-2014. Infect Control Hosp Epidemiol. 2016;37:1288-301.

12. Roger C, Nucci B, Louart B, Friggeri A, Knani H, Evrard A, et al. Impact of $30 \mathrm{mg} / \mathrm{kg}$ amikacin and $8 \mathrm{mg} / \mathrm{kg}$ gentamicin on serum concentrations in critically ill patients with severe sepsis. J Antimicrob Chemother. 2016;71:208-12.

13. Roger C, Nucci B, Molinari N, Bastide S, Saissi G, Pradel G, et al. Standard dosing of amikacin and gentamicin in critically ill patients results in variable and subtherapeutic concentrations. Int J Antimicrob Agents. 2015;46:21-7.

14. Luyt CE, Clavel M, Guntupalli K, Johannigman J, Kennedy JI, Wood C, et al. Pharmacokinetics and lung delivery of PDDSaerosolized amikacin (NKTR-061) in intubated and mechanically ventilated patients with nosocomial pneumonia. Crit Care. 2009;13:R200.

15. Kollef MH, Ricard JD, Roux D, Francois B, Ischaki E, Rozgonyi $\mathrm{Z}$, et al. A randomized trial of the amikacin fosfomycin inhalation system for the adjunctive therapy of Gram-negative ventilatorassociated pneumonia IASIS trial. Chest. 2017;151:1239-46.

16. Rello J, Sole-Lleonart C, Rouby JJ, Chastre J, Blot S, Poulakou $\mathrm{G}$, et al. Use of nebulized antimicrobials for the treatment of respiratory infections in invasively mechanically ventilated adults: a position paper from the European Society of Clinical Microbiology and Infectious Diseases. Clin Microbiol Infect Dis. 2017;23:629-39.

17. Niederman MS, Alder J, Bassetti M, et al. Inhaled amikacin adjunctive to intravenous standard-of-care antibiotics in mechanically ventilated patients with Gram-negative pneumonia (INHALE): a double-blind, randomised, placebo-controlled, phase 3, superiority trial. Lancet Infect Dis. 2020;20:330-40. 
18. Leconte P, Potel G, Peltier P, Horeau D, Caillon J, Juvin ME, et al. Lung distribution and pharmacokinetics of aerosolized tobramycin. Am Rev Respir Dis. 1993;147:1279-82.

19. Elman M, Goldstein I, Marquette CH, Wallet F, Lenaour G, Rouby $\mathrm{JJ}$, et al. Influence of lung aeration on pulmonary concentrations of nebulized and intravenous amikacin in ventilated piglets with severe bronchopneumonia. Anesthesiology. 2002;97:199-206.

20. Rouby JJ, Monsel A, Ehrmann S, Bouglé A, Laterre PF. The INHALE trial: multiple reasons for a negative result. Lancet Infect Dis. 2020;20(7):778-9.

21. Bataillon V, Lhermitte M, Lafitte JJ, Pommery J, Roussel P. The binding of amikacin to macromolecules from the sputum of patients suffering from respiratory diseases. J Antimicrob Chemother. 1992;29:499-508.

22. Huang JX, Blaskovich MA, Pelingon R, Ramu S, Kavanagh A, Elliott AG, et al. Mucin binding reduces colistin antimicrobial activity. Antimicrob Agents Chemother. 2015;59:5925-31.

23. van't Veen A, Mouton JW, Gommers D, Kluytmans JA, Dekkers $\mathrm{P}$, Lachmann B. Influence of pulmonary surfactant on in vitro bactericidal activities of amoxicillin, ceftazidime, and tobramycin. Antimicrob Agents Chemother. 1995;39:329-33.

24. Bodem CR, Lampton LM, Miller DP, Tarka EF, Everett ED. Endobronchial $\mathrm{pH}$. Relevance of aminoglycoside activity in Gram-negative bacillary pneumonia. Am Rev Respir Dis. 1983;127:39-41.

25. Kim KC. Role of epithelial mucins during airway infection. Pulm Pharmacol Ther. 2012;25:415-9.

26. Schlessinger D. Failure of aminoglycoside antibiotics to kill anaerobic, low-pH, and resistant cultures. Clin Microbiol Rev. 1988;1:54-9.

27. Wiegand I, Hilpert K, Hancock RE. Agar and broth dilution methods to determine the minimal inhibitory concentration (MIC) of antimicrobial substances. Nat Protoc. 2008;3:163-75.

28. Hasselmann C, European Soc Clinical M. Determination of minimum inhibitory concentrations (MICs) of antibacterial agents by broth dilution. Clin Microbiol Infect. 2003;9:7.

29. Drusano GL, Liu W, Fikes S, Cirz R, Robbins N, Kurhanewicz $\mathrm{S}$, et al. Interaction of drug- and granulocyte-mediated killing of Pseudomonas aeruginosa in a murine pneumonia model. J Infect Dis. 2014;210:1319-24.

30. Hunt BE, Weber A, Berger A, Ramsey B, Smith AL. Macromolecular mechanisms of sputum inhibition of tobramycin activity. Antimicrob Agents Chemother. 1995;39:34-9.

31. Raymondos K, Leuwer M, Haslam PL, Vangerow B, Ensink M, Tschorn $\mathrm{H}$, et al. Compositional, structural, and functional alterations in pulmonary surfactant in surgical patients after the early onset of systemic inflammatory response syndrome or sepsis. Crit Care Med. 1999;27:82-9.

32. Neely MN, van Guilder MG, Yamada WM, Schumitzky A, Jelliffe RW. Accurate detection of outliers and subpopulations with Pmetrics, a nonparametric and parametric pharmacometric modeling and simulation package for R. Ther Drug Monit. 2012;34:467-76.

33. Gumbo T, Louie A, Deziel MR, Parsons LM, Salfinger M, Drusano GL. Selection of a moxifloxacin dose that suppresses drug resistance in Mycobacterium tuberculosis, by use of an in vitro pharmacodynamic infection model and mathematical modeling. J Infect Dis. 2004;190:1642-51.
34. Landry RM, An D, Hupp JT, Singh PK, Parsek MR. Mucin-Pseudomonas aeruginosa interactions promote biofilm formation and antibiotic resistance. Mol Microbiol. 2006;59:142-51.

35. Co JY, Cárcamo-Oyarce G, Billings N, Wheeler KM, Grindy SC, Holten-Andersen N, et al. Mucins trigger dispersal of Pseudomonas aeruginosa biofilms. NPJ Biofilms Microbiomes. 2018;4:23. https://doi.org/10.1038/s41522-018-0067-0.

36. Sun E, Gill EE, Falsafi R, Yeung A, Liu SJ, Hancock REW. Broad-spectrum adaptive antibiotic resistance associated with Pseudomonas aeruginosa mucin-dependent surfing motility. Antimicrob Agents Chemother. 2018;62(9):e00848-e918. https://doi. org/10.1128/AAC.00848-18.

37. Lebeaux D, Chauhan A, Letoffe S, Fischer F, de Reuse H, Beloin $\mathrm{C}$, et al. $\mathrm{pH}$-mediated potentiation of aminoglycosides kills bacterial persisters and eradicates in vivo biofilms. J Infect Dis. 2014;210:1357-66.

38. Shields RK, Clancy CJ, Press EG, Nguyen MH. Aminoglycosides for treatment of bacteremia due to carbapenem-resistant Klebsiella pneumoniae. Antimicrob Agents Chemother. 2016;60:3187-92.

39. Vidal L, Gafter-Gvili A, Borok S, Fraser A, Leibovici L, Paul M. Efficacy and safety of aminoglycoside monotherapy: systematic review and meta-analysis of randomized controlled trials. J Antimicrob Chemother. 2007;60:247-57.

40. Powell J, Garnett JP, Mather MW, Cooles FAH, Nelson A, Verdon B, et al. Excess mucin impairs subglottic epithelial host defense in mechanically ventilated patients. Am J Respir Crit Care Med. 2018;198:340-9.

41. Planquette B, Timsit JF, Misset BY, Schwebel C, Azoulay E, Adrie $\mathrm{C}$, et al. Pseudomonas aeruginosa ventilator-associated pneumonia predictive factors of treatment failure. Am J Respir Crit Care Med. 2013;188:69-76.

42. Rees VE, Bulitta JB, Oliver A, Tsuji BT, Rayner CR, Nation RL, et al. Resistance suppression by high-intensity, short-duration aminoglycoside exposure against hypermutable and non-hypermutable Pseudomonas aeruginosa. J Antimicrob Chemother. 2016;71:3157-67.

43. Padra M, Adamczyk B, Benktander J, Flahou B, Skoog EC, Padra $\mathrm{JT}$, et al. Helicobacter suis binding to carbohydrates on human and porcine gastric mucins and glycolipids occurs via two modes. Virulence. 2018;9:898-918.

44. Karlsson NG, Nordman H, Karlsson H, Carlstedt I, Hansson GC. Glycosylation differences between pig gastric mucin populations: a comparative study of the neutral oligosaccharides using mass spectrometry. Biochem J. 1997;326:911-7.

45. Perez-Vilar J, Hill RL. The structure and assembly of secreted mucins. J Biol Chem. 1999;274:31751-4.

46. Wiseman LR, Bryson HM. Porcine-derived lung surfactant. A review of the therapeutic efficacy and clinical tolerability of a natural surfactant preparation (Curosurf) in neonatal respiratory distress syndrome. Drugs. 1994;48:386-403. 